Journal of the Rubber Research Institute of Sri Lanka, (2005) 87, 1-6

\title{
Adaptability of recently recommended rubber clones for agro-climatic variability of Sri Lanka
}

\author{
S P Withanage*, D P S T G Attanayake** and K B A Karunasekara* \\ Received 14 September 2004; Accepted 04 August 2005
}

\begin{abstract}
Fifteen new Hevea clones which were planted in eight different sites in 1998 were studied to select stable clones for wide range of agro-climatic variability. The analysis of variance indicated the presence of significant genetic, environmental and genotype environment interaction for $5^{\text {th }}$ year girth measurement. Variance of clones over environments used as the stability index. Mean stability and the mean performance were used to categorized the fifteen clones into four groups with different levels of mean performances and stabilities. The clones RRISL 215 and RRISL 217 were shown to be highly stable over all the environments with high mean performance.
\end{abstract}

Key words: agro-climatic variability, clones, Hevea brasiliensis

\section{Introduction}

It is a common accepted fact that the performance of a crop varies with the environment. Environment affects the crop growth and yield. Most of the crops have been adapted to the environmental conditions, in which they have been developed. These environmental conditions comprise of factors such as rainfall, light (sunshine) temperature, wind, humidity and soil. More over these factors are unpredictable and can not be controlled.

Rubber (Hevea brasiliensis) is an economically important crop in the humid tropics, not only as a natural rubber producer, but also as a sustainable agro-forestry system, which is almost equivalent to native rainforest system. It forms an important tree crop plantation, which provides reproducible stable ecological system and gives high economic value, than natural forests, by producing natural rubber $(1: 4$ cis polyisoprene) which is ecological friendly industrial raw material. Hevea brasiliensis is mainly grown in the low country wet zone (WL) in Sri Lanka. Recently government has taken steps to expand rubber cultivation in relatively drier areas in Monaragala and Ampara districts. Now it is well known that the

* Rubber Research Institute of Sri Lanka, Dartonfield, Agalawatta

** Faculty of Agriculture and Plantation Management, Wayamba University of Sri Lanka, Makandura 


\section{Adaptability of recently recommended clones for climatic variability}

climate of the earth is changing. This will make changes in Agro-climatic conditions in Sri Lanka with associated changes in growth and economic performance of rubber. It was reported that Sri Lanka would experience extreme rainfall intensities and warmer temperatures due to this climatic changes and possibility of ten percent increase in the length of dry and wet seasons per year, in the main planting areas (Plantation World - December 2002).

Possible solution to overcome this situation will be to identify, select and recommend environmentally stable clones, which can yield in a wide range of climatic conditions. In addition identification of highly adaptable clones for particular environmental conditions is another approach in maximizing the returns from these rubber plantations in view of the possible changes in agroclimatic conditions resulting from the global climatic change.

\section{Materials and Methods \\ Plant material}

For this study Ten RRISL clones Viz. RRISL 201, 205, 206, 210, 215, 217, 218, 219, 220 and RRIC 130 and five foreign clones, RRII 105,RRIM 712, PB 261,GPS1 and HEIKEN- 2 introduced from other rubber growing countries were selected.

\section{Experimental location and design}

This experiment has been established in 1998 in eight different climatic regions given below, as a complete randomized design with 20 single tree plots from each clone per site.

\begin{tabular}{lll}
\hline Site & $\begin{array}{l}\text { Planting } \\
\text { region }\end{array}$ & $\begin{array}{l}\text { Agro-climatic } \\
\text { region and } \\
\text { average } \\
\text { rainfall (mm) }\end{array}$ \\
\hline Sorana & Kalutara & WL - 3 $>1525$ \\
Muwankanda & Kurunegala & I L - 1 $>1020$ \\
Palmgarden & Ratnapura & WL - 1 $>2540$ \\
Ganepalla & Awissawella & WL - 1 $>2540$ \\
Baddegama & Galle & WL - 3 $>1525$ \\
Bibile & Monaragala & I L - 2 >1125 \\
Atala & Kegalle & WL - 2 >1900 \\
Pelmadulla & Ratnapura & WL - 2 $>1900$ \\
\hline
\end{tabular}

\section{Data collection and analysis}

Girth measurements commenced at the end of $5^{\text {th }}$ year (2003) after planting, at a height of $120 \mathrm{~cm}$ from the highest point of the bud-union. Rainfall data were recorded in all sites. Analysis of the data was done by SAS 1990 .

The scatter diagram as described by Jayasekera (1983) obtained by plotting the mean performance and stability of clones, was used as the basis for selection for stability and mean performance of the growth of the rubber clones.

\section{Results and Discussion}

Mean girth of clones for each experimental site was subjected to statistical analysis, to study the effects of genotypes, environment, and genotype and environment interaction.

The results of the analysis of variance (ANOVA) given in Table 1 showed that the clone differences, site 


\section{S P Withanage et al.}

differences and their interaction components were highly significant for the character under study. The significant differences between clones showed that there were genetic differences among those fifteen clones. Significant differences between sites means indicated that there existed differences between the sites in which clones were tested. The significant interaction component showed that the individual clone behaved differentially in the different environments in which they were tested.

Genotypes, environmental and genotype and site interaction variance components as a percentage of the total variance were estimated and presented in Table 2.

The genetic and the environment components of the girth were 35.84 and 57.02 percent respectively. The genetic and environment interaction was 7.12 percent and the smallest variance component of the girth. From the same experiment Ranasinghe et. al (2003) has reported genotype, environment and interaction component as $13.53,85.85$, 3.61. Percent respectively. It is seen that the environment component has decreased by 28.83 percent where as compared to $3^{\text {rd }}$ year. Jayasekara et al (1994) also have reported the increasing genotype component and decreasing environment component in different Hevea clones, at their early growth stage.

The mean performance of all clones in each environment (mean girth over all sites) can be used as a biological measure to characterize the environment (Jayasekera et. al 1977). Ganepalla showed the highest site mean (43.386) and Bibile (29.8666) showed the lowest site mean. RRISL 05(42.05) had the highest mean performance value while GPS1 (14.3) had the lowest when clones were averaged over environments (Table 3).

Table 1. Results of the analysis of variance

\begin{tabular}{lccc}
\hline Item & df & Mean square & Significance \\
\hline Clones & 14 & 1545.8 & $* * *$ \\
Sites & 7 & 2226.34 & $* * *$ \\
Clones $\times$ Site interaction & 98 & 506.74 & $* * *$ \\
\hline & & $* * * 0.1 \%$ &
\end{tabular}

Table 2. The percentage contribution of genotype, environment and genotype $\times$ environmental interaction components to the total variance

\begin{tabular}{lc}
\hline Component & Girth \% \\
\hline Genotypic & 35.84 \\
Environment & 57.02 \\
Genotypic $\times$ Environment & 7.12 \\
\hline
\end{tabular}


Table 3. The mean performance and mean variance (girth in $\mathrm{cm}$ )

\begin{tabular}{|c|c|c|c|c|c|c|c|c|c|c|}
\hline Clone & Atale & Baddegama & Ganepalla & Palmadulla & Muwankanda & Sorana & Palmgarden & Bibile & Clone mean & Variance \\
\hline GPS 1 & 34.95 & 31.42 & 35.4 & 33.07 & 33.75 & 27.75 & 25.4 & 27.61 & 31.16 & 14.31 \\
\hline HN2 & 38.42 & 36.88 & 36.25 & 33.5 & 38.92 & 34.5 & 29.16 & 29.14 & 34.59 & 14.54 \\
\hline PB 260 & 42.31 & 39.96 & 42.69 & 38.63 & 38.46 & 39.29 & 35.92 & 27.91 & 38.14 & 21.80 \\
\hline RC 130 & 38.15 & 38.3 & 41.53 & 39.76 & 36.17 & 41.7 & 35.91 & 29.65 & 37.64 & 15.11 \\
\hline RI 105 & 43.18 & 42.36 & 43.23 & 41.46 & 38.62 & 37.94 & 32.07 & 27.78 & 38.33 & 32.04 \\
\hline RL 201 & 46.23 & 44.76 & 49.52 & 46.15 & 44.72 & 43.88 & 36.33 & 32.11 & 42.96 & 33.25 \\
\hline RL 205 & 47.55 & 45.0 & 55.11 & 46.88 & 46.94 & 42.15 & 38.42 & 33.61 & 44.45 & 42.11 \\
\hline RL 206 & 48.73 & 45.47 & 52.1 & 41.47 & 46.0 & 43.66 & 39.86 & 34.78 & 44.00 & 28.97 \\
\hline RL 210 & 42.84 & 39.02 & 41.43 & 41.5 & 36.11 & 36.8 & 33.38 & 27.6 & 37.33 & 25.63 \\
\hline RL 215 & 40.79 & 40.17 & 41.07 & 38.15 & 41.25 & 39.77 & 34.44 & 31.21 & 38.73 & 16.79 \\
\hline RL 217 & 41.86 & 40.03 & 46.66 & 38.67 & 38.33 & 40.92 & 33.6 & 31.6 & 38.95 & 22.29 \\
\hline RL 218 & 45.32 & 43.73 & 49.58 & 39.63 & 42.07 & 38.85 & 31.92 & 30.94 & 40.25 & 40.94 \\
\hline RL 219 & 43.87 & 41.6 & 47.05 & 40.46 & 38.52 & 39.04 & 34.92 & 30.32 & 39.47 & 26.83 \\
\hline RL 220 & 38.75 & 41.08 & 35.26 & 38.35 & 40.31 & 37.12 & 27.15 & 26.19 & 35.52 & 33.14 \\
\hline RM 712 & 37.5 & 37.69 & 30.91 & 36.33 & 36.55 & 37.07 & 26.47 & 27.55 & 33.75 & 22.08 \\
\hline Mean & 42.03 & 40.49 & 43.38 & 39.60 & 39.78 & 38.69 & 32.99 & 29.86 & 38.35 & 25.99 \\
\hline
\end{tabular}


S P Withanage et al.

When selecting a clone, it is important to consider high mean performance as well as the stability. The variance of clone means over environments could be used as an index of stability of that clone. Clones with low variance are considered to be stable (Jayasekera et al., 1977). The mean variance (25.9929) of the fifteen clones was used as the point of turncation in the selection of stability and the mean girth of all clones or grand mean (38.35) was used as the point of turncation in the selection of performance (Jayasekera 1982). With respect to performance high-performed clones should have higher mean than the grand mean which is considered as the mean performance of the clonal population. Thus there are four combinations of different levels of stabilities as described in Table 4.

Therefore the mean girth and the variances of fifteen clones in eight sites (Table 3) were grouped and given in Table 5.

Table 4. Four group with different levels of mean performance and stability

\begin{tabular}{ll}
\hline Description & Condition \\
\hline High stability with high mean performance & $\begin{array}{l}\text { Below average variance/above average clone } \\
\text { mean }\end{array}$ \\
High stability with low mean performance & $\begin{array}{l}\text { Below average variance/below average clone } \\
\text { mean }\end{array}$ \\
Low stability with High mean performance & $\begin{array}{l}\text { Above average variance/above average clone } \\
\text { mean }\end{array}$ \\
Low stability with low mean Performance & $\begin{array}{l}\text { Above average variance/below average clone } \\
\text { mean }\end{array}$ \\
\hline
\end{tabular}

Table 5. Selection of Hevea clones for stability and performance in growth under agroclimatic variability

\begin{tabular}{ll}
\hline $\begin{array}{l}\text { Level of growth performance and } \\
\text { stability }\end{array}$ & Clone \\
\hline High stability with high mean performance & RRISL 215, RRISL 217 \\
Low stability with high mean performance & RRISL 201, RRISL 205, RRISL 206, \\
& RRISL218, RRISL219 \\
High stability with low mean performance & GPS 1, HN 2, PB 260, RRIC 130, RRISL 210, \\
& RRIM712 \\
Low stability with low mean performance & RRISL 220, RRII 105 \\
\hline
\end{tabular}


Adaptability of recently recommended clones for climatic variability

Out of those fifteen clones, RRISL 215 and RRISL 217 proved to be the most stable with high mean performance. Though RRISL 205 showed the highest mean performance (44.45) it was the least stable clone (42.11). Ranasinghe et al. (2003) also classified this clone as a highly environmental sensitive clone. RRISL 206 showed high mean performance next to RRISL 205 but its stability was just below the average. RRIC 130 was the highest stable clone with mean performance just below the average.

\section{Conclusion}

Based on the result of this study the fifteen clones were grouped into four categories having different levels of stabilities and mean performance (Table 5). These results suggest that it is possible to select highly stable rubber clones to withstand the range of environmental conditions considered in this study. RRISL 215 and RRISL217 were shown to be highly stable with high mean performance over the all environments.

\section{Acknowledgement}

The authors are grateful to $\mathrm{Mr}$ K W Rupatunge, Mr I D M J Sarath Kaumara and $\mathrm{Mr} \mathrm{H} \mathrm{P}$ Peries for the technical assistance given during the study and Mrs S D P K L Peiris for assistance in the preparation of this manuscript.

\section{References}

Finlay, K W and Wilkinson, G N (1963). The analysis of adaptation in a plant breeding programme. Australian Journal of Agricultural Research 14, 742-754.

Jayasekera, N E M, Samaranayake, P and Karunasekera, K B (1977). Initial studies on the nature of genotype-environment interaction in some Hevea clones. Journal of the Rubber Research Institute of Sri Lanka 54, 33-42.

Jayasekera, N E M, Karunasekera, K B and Kersey, M J (1994). Genetics of production traits in Hevea brasiliensis (rubber). 1. Changes in genetical control with age. Heredity 73, 650-656.

Jayasekera, N E M (1982). A basis of selecting Hevea clones stable to unpredictable agro-climatic variability. Silvae Genetica 32, 181-184.

Plantation World (2002). The Journal of the Planters Association of Ceylon Vol.1. No.4, 15-16.

Ranasinghe, W S, Attanayake, D P S T G and Jayasekera, N E M (2003). Variation of growth performance of recommended rubber (Hevea brasiliensis) clones in different rubber growing regions in Sri Lanka. Proceedings of $3^{\text {rd }}$ Agricultural Research Symposium.

Address for correspondence: Mrs S P Withanage, Asst. Geneticist and Asst. Plant Breeder, Rubber Research Institute of Sri Lanka, Nivitthigalakele, Matugama, Sri Lanka.

E-mail: dirrri@sltnet.lk 